\title{
Diversity Among a Wide Asian Collection of Bitter Gourd Landraces and their Genetic Relationships with Commercial Hybrid Cultivars
}

\author{
Narinder P.S. Dhillon ${ }^{1}$ and Supannika Sanguansil \\ World Vegetable Center, East and Southeast Asia/Oceania, Kasetsart University, Kamphaeng Saen, \\ Nakhon Pathom 73140, Thailand \\ Roland Schafleitner and Yen-Wei Wang \\ Biotechnology, World Vegetable Center, P.O. Box 42, Shanhua, Tainan 741, Taiwan \\ James D. McCreight \\ U.S. Department of Agriculture, Agricultural Research Service, U.S. Agricultural Research Station, \\ 1636 E. Alisal Street, Salinas, CA 93905
}

\begin{abstract}
AdDitional INDEX words. Momordica charantia, genetic diversity, landraces, plant breeding, resistance, simple sequence repeats

Abstract. We report here the genetic characterization of bitter gourd (Momordica charantia) based on polymorphisms of 50 simple sequence repeat (SSR) loci in 114 accessions that included landraces, breeding lines, and commercial open-pollinated and $F_{1}$ hybrid cultivars widely grown in Asia. Neighbor-joining tree analysis revealed a high level of genetic variability in the collection. The 114 accessions formed three subpopulations represented by five clusters. Distribution of accessions across the five clusters reflected their geographic origin to a large extent. South Asian accessions originating from India, Bangladesh, and Pakistan were more closely related to each other than to any other geographical group. Likewise, southeast Asian accessions that originated from Cambodia, Vietnam, Indonesia, and Philippines were grouped together. Accessions that originated from Taiwan were genetically distinct and grouped separately. A landrace from Laos was genetically close to the accessions from Thailand and genetically distinct from the rest of the accessions. White-fruited genotypes were genetically distinct from green- and dark green-fruited genotypes. Low- and medium-bitter accessions were more similar to each other than to the high-bitter genotypes. Accessions with cylindrical fruit were genetically distinct from those with spindle or elongated fruit. Commercial cultivars in each cluster were closely related, which indicated a narrowing of the bitter gourd genetic base in Asia in response to market demands for uniformity and yield. Use of diverse germplasm resources in bitter gourd breeding will help in sustainable breeding and production.
\end{abstract}

Bitter gourd is a commercially and nutritionally important vegetable in Asia, where $\approx 340,000$ ha are cultivated annually (McCreight et al., 2013). Its cultivation is becoming more popular in several African countries, such as Ghana, Zambia, Congo, and Madagascar for local consumption or for export to Europe and the Middle East to meet the demand of emigrant Asian communities. It is also cultivated in the southern United States and Australia (Northern Territory, Queensland, New South Wales, Victoria), where Asian hybrid cultivars are grown as a niche product for consumption chiefly by ethnic communities from Asia (Morgan and Midmore, 2002).

Bitter gourd fruit is a good dietary source of beta-carotene, vitamin $\mathrm{C}$, folic acid, magnesium, phosphorus, and potassium (Yuwai et al., 1991). It is often used in folk medicine in Asia to manage type 2 diabetes, a noncommunicable disease that currently affects 347 million people worldwide (World Health Organization, 2016). Bitter gourd fruit contains compounds that have the potential to improve insulin sensitivity, lower blood glucose, and help regulate postprandial/intestinal glucose uptake (Krawinkel and Keding, 2006). Fiber (Uebanso et al., 2007), an insulin-like protein (Khanna et al., 1981), saponins (Klomann et al., 2010; Oishi et al., 2007), triterpenes (Tan et al.,

Received for publication 21 Mar. 2016. Accepted for publication 29 June 2016. ${ }^{1}$ Corresponding author. E-mail: narinder.dhillon@worldveg.org.
2008), and lipids (Klomann et al., 2010) in bitter gourd fruit have been linked to antidiabetic effects (see Tan et al., 2016 for additional health benefits of bitter gourd).

Recent biogeographic analyses show that $M$. charantia originated from Africa (Schaefer and Renner, 2010), but its place of domestication remains unknown, though southern China or eastern India have been proposed (Walters and DeckerWalters, 1988). The earliest recorded reference to cultivated forms of M. charantia in China was in $1370 \mathrm{CE}$ (Yang and Walters, 1992). Wild or small-fruited, cultivated forms are mentioned in Ayurvedic texts written in Sanskrit from 2000 to 200 BCE by Indo-Aryan cultures (Decker-Walters, 1999).

Bitter gourd breeders have been effective in improving the bitter gourd fruit yield and quality in the last two decades (Behera et al., 2010). Consumer preferences for fruit bitterness, color, shape, skin pattern, and size vary between and within countries. For example, consumers in south Asia like highly bitter fruit, whereas less bitter fruit are preferred in southeast Asian countries; e.g., Thailand and Vietnam. Lightgreen and medium-long, spindle fruit are liked by consumers in Vietnam, whereas long cylindrical and smooth fruit with light-green color are preferred in Thailand. South Asian consumers like small-to-medium size, dark-green, spindleshaped fruit with spiny exterior surfaces. White fruit are used in soups in Taiwan and India. 
Spiny fruit is dominant over smooth (Vahab, 1989). Green fruit color is dominant over white (Hu et al., 2002) and is controlled by two genes (Liu et al., 2005). Bitterness of fruit is controlled by a single gene, with more bitterness dominant to less (Suribabu et al., 1986). Saponins, momordicosides K and $\mathrm{L}$, as well as momordicines I and II cause the bitter taste (Harinantenaina et al., 2006).

A major part of plant breeding success has come by employing pedigree breeding through recombination and subsequent selection during inbreeding of elite $\times$ elite crosses, and further use of derived inbreds in hybrid development programs. This approach was adopted due to the constant pursuit of two horticultural traits desired by growers, such as earliness and high marketable yield, which results from high fruit number and high fruit weight, and improvement of traits desired by consumers, such as fruit color, shape, size, and skin pattern, which became strong forces in a reduction of genetic diversity in commercially grown bitter gourd cultivars. Improved hybrid cultivars lead to further reduction in genetic diversity through displacement of landraces. For example, a significant bitter gourd area in India and Bangladesh is planted to the cultivar Palee, which is a south Asian market type: dull green, medium long with blunt spines (A. Masud, personal communication). A similar trend is developing with other market types, such as the southeast Asian type, where there is evidence of market dominance by a few hybrid cultivars. Performance-driven selection and grower preferences result in a narrow genetic base (Duvick, 2005) that can increase vulnerability to disease and insect outbreaks (Keneni et al., 2012). Plant breeders must make better use of existing bitter gourd diversity to develop improved bitter gourd cultivars that are genetically broad based. Assessment of the genetic diversity in crop collections, such as the World Vegetable Center bitter gourd holdings, is a critical component of germplasm characterization for subsequent utilization by plant breeders.

Molecular analyses of $M$. charantia have been conducted using limited numbers of accessions that originated from either India or China (Gaikwad et al., 2008; Ji et al., 2012; Saxena et al., 2015). The genebank of the World Vegetable Center, Taiwan, has a sizeable collection of bitter gourd germplasm from more than 15 countries. Molecular and morphological characterizations of this germplasm in comparison with widely grown commercial cultivars are important for continued development of improved and genetically diverse bitter gourd cultivars. Herein, we report molecular and morphological assessments of the genetic diversity of the World Vegetable Center bitter gourd collection based on polymorphisms of 50 SSR loci in 114 landraces, breeding lines, and commercial cultivars widely grown in Asia, and five fruit traits evaluated in three seasons.

\section{Materials and Methods}

Plant materials. One hundred and fourteen PIs comprised lines derived from accessions and landraces through inbreeding, open-pollinated lines released by the World Vegetable Center, and commercial hybrid cultivars, collectively referred to as cultigens were used for the study (Table 1). The germplasm originated from 11 countries in Asia, and represents all market types of bitter gourd based on fruit size, shape, skin pattern, and color (Table 1).
Fruit trait characterization. The 114 cultigens were evaluated for five fruit traits in 2013, 2014, and 2015 at the World Vegetable Center, East and Southeast Asia/Oceania, Research and Training Station, Kasetsart University, Kamphaeng Saen, Nakhon Pathom, Thailand. Entries were planted in a single block with row spacing of $1.6 \mathrm{~m}$, within-row spacing of $1 \mathrm{~m}$, and five plants per plot. Five marketable fruit of each cultigen were harvested for evaluation of five fruit traits: 1) shape $=$ cylindrical, spindle, elongated; 2) color $=$ green, light green, medium green, dark green, white; 3) skin pattern = smooth, spiny; 4) bitterness = low, medium, high; and 5) length = long, medium, short.

Fruit bitterness was evaluated using fresh marketable fruit of each cultigen, washed and cut into small $(\approx 3 \mathrm{~g})$ pieces, and used for organoleptic assessments by a five-person taste panel. Three classes of bitterness were recorded: high, medium, and low. The evaluators rinsed their mouth with fresh water after each sample. We categorized the cultigens by different market segments according to the length of the fruit: short segment $(<10 \mathrm{~cm})$, medium segment $(10-20 \mathrm{~cm})$, and long segment $(>20$ $\mathrm{cm})$. Pooled data from the 3 years were used for describing fruit shape, color, skin pattern, length, and bitterness.

SSR MARKER DESIGN. Two hundred fifty-five thousand publically available sequencing reads of a normalized $M$. charantia seed transcriptome produced from poly-A-enriched total RNA (Yang et al., 2010) were used to develop SSR markers. The raw sequence reads were cleaned from adaptor sequences using SeqClean (Dana-Farber Cancer Institute, 2005); repeats were masked (Smit et al., 1997), and the reads were assembled with CAP3 (Huang and Madan, 1999) to 20,290 contigs and 23,361 singletons. The contigs and singletons were mined for dimer, trimer, tetramer and composite SSR motifs with the SSR Locator script (da Maia et al., 2008). Primers for polymerase chain reaction (PCR) amplification of DNA fragments containing SSR motifs were designed with the Primer3 program incorporated in the SSR Locator. One hundred SSR markers were randomly chosen for amplification and polymorphism testing on 16 diverse $M$. charantia and Momordica balsamina accessions. The polymorphic information content (PIC) of the markers was determined in PowerMarker V3.0 (Liu and Muse, 2005), where the PIC value of an 1-allele locus was calculated as $\mathrm{PIC}=1-\sum_{i=1}^{l} \mathrm{P}_{i}^{2}-\sum_{i=1}^{l-1} \sum_{j=i+1}^{l} 2 \mathrm{P}_{i}^{2} \mathrm{P}_{j}^{2}$, where $\mathrm{P} i$ and $\mathrm{P} j$ are the population frequency of the $i$ th and $j$ th allele (Nagy et al., 2012). From the markers that amplified reliably in the test set, 50 markers with a PIC greater than 0.1 were chosen for genotyping (Table 2).

DNA ISOLATION AND SSR GENOTYPING AND DATA ANALYSIS. Genomic DNA was isolated from fresh tissue of young leaves using the protocol of Fulton et al. (1995).

PCR amplifications were performed in $10-\mu \mathrm{L}$ reactions containing $0.2 \mu \mathrm{M}$ of each primer, $200 \mu \mathrm{M}$ of deoxyribonucleotides, $50 \mathrm{~mm} \mathrm{KCl}, 10 \mathrm{~mm}$ Tris $\mathrm{HCl}$ (pH 8.3), $1.5 \mathrm{~mm} \mathrm{MgCl}_{2}$, $25 \mathrm{ng}$ of DNA and 0.5 units of Taq DNA polymerase. The SSR amplifications were conducted in a PTC 200 DNA engine thermal cycler (MJ Research, Waltham, MA). The temperature profile used for PCR amplification comprised $94{ }^{\circ} \mathrm{C}$ for $5 \mathrm{~min}$, followed by 30 cycles of $94{ }^{\circ} \mathrm{C}$ for $30 \mathrm{~s}, 55^{\circ} \mathrm{C}$ for $45 \mathrm{~s}, 72^{\circ} \mathrm{C}$ for $45 \mathrm{~s}$, and finally by $7 \mathrm{~min}$ at $72{ }^{\circ} \mathrm{C}$ for the final extension. PCR products $(3 \mu \mathrm{L})$ were analyzed on $6 \%$ nondenaturing polyacrylamide gel in $0.5 \times$ Tris/Borate/EDTA buffer. After 
Table 1. Cultigen code, origin, and five fruit traits of 114 bitter gourd cultigens (accessions and landraces through inbreeding, open-pollinated lines released by the World Vegetable Center, and commercial hybrid cultivars) subjected to genetic diversity analysis based on simple sequence repeat markers. Fruit characteristics based on field evaluations in 2013, 2014, and 2015 at Kamphaeng Saen, Thailand.

\begin{tabular}{|c|c|c|c|c|c|c|c|}
\hline \multirow[b]{2}{*}{ Cultigen } & \multirow[b]{2}{*}{ Code } & \multirow[b]{2}{*}{ Origin $^{z}$} & \multicolumn{5}{|c|}{ Fruit } \\
\hline & & & Shape & Color & Skin pattern & Bitterness & Market segment $^{\mathrm{y}}$ \\
\hline THMC 115 & 1 & Cambodia & Cylindrical & Light green & Smooth & Low & Long \\
\hline THMC 116 & 2 & Cambodia & Cylindrical & Green & Smooth & Medium & Long \\
\hline THMC 122-1 & 4 & Cambodia & Spindle & Green & Smooth & Low & Medium \\
\hline THMC 126 & 5 & Cambodia & Cylindrical & Light green & Smooth & Low & Medium \\
\hline THMC 108 & 6 & Indonesia & Elongated & Light green & Spiny & Low & Long \\
\hline THMC 111 & 8 & Indonesia & Spindle & Green & Smooth & Low & Medium \\
\hline THMC 112 & 9 & Indonesia & Spindle & White & Spiny & Medium & Medium \\
\hline THMC 114 & 10 & Laos & Spindle & Green & Spiny & Low & Short \\
\hline THMC 29 & 11 & Philippines & Spindle & Green & Smooth & Low & Medium \\
\hline THMC 32 & 12 & Philippines & Spindle & Green & Smooth & Low & Medium \\
\hline THMC 33 & 13 & Philippines & Spindle & Dark green & Smooth & Medium & Medium \\
\hline THMC 44 & 18 & Philippines & Spindle & Medium green & Smooth & Low & Long \\
\hline THMC 47 & 19 & Philippines & Spindle & Green & Spiny & Medium & Short \\
\hline THMC 48 & 20 & Philippines & Spindle & Green & Smooth & High & Short \\
\hline THMC 49 & 21 & Philippines & Spindle & Green & Spiny & Low & Short \\
\hline THMC 53-2 & 22 & Philippines & Spindle & Green & Smooth & Low & Medium \\
\hline THMC 54 & 23 & Philippines & Spindle & Medium green & Spiny & Low & Short \\
\hline THMC 55 & 24 & Philippines & Spindle & Light green & Spiny & Low & Short \\
\hline THMC 101 & 25 & Taiwan & Spindle & Light green & Spiny & Low & Short \\
\hline THMC 102 & 26 & Taiwan & Spindle & Green & Spiny & Medium & Short \\
\hline THMC 103-1 & 27 & Taiwan & Spindle & Light green & Spiny & Medium & Short \\
\hline THMC 104 & 28 & Taiwan & Spindle & Light green & Spiny & Low & Short \\
\hline THMC 15 & 36 & Thailand & Spindle & Light green & Spiny & Low & Short \\
\hline THMC 17 & 37 & Thailand & Spindle & Green & Spiny & Low & Short \\
\hline THMC 19 & 38 & Thailand & Spindle & Light green & Spiny & Low & Short \\
\hline THMC 22 & 39 & Thailand & Spindle & Green & Spiny & Low & Short \\
\hline THMC 23 & 40 & Thailand & Spindle & Green & Spiny & Low & Short \\
\hline THMC 25 & 41 & Thailand & Spindle & Medium green & Smooth & Low & Medium \\
\hline THMC 26-1 & 42 & Thailand & Spindle & Medium green & Spiny & Low & Medium \\
\hline THMC 58 & 43 & Vietnam & Spindle & Green & Smooth & Medium & Medium \\
\hline THMC 60-2 & 44 & Vietnam & Spindle & White & Smooth & Low & Medium \\
\hline THMC 62 & 45 & Vietnam & Spindle & Green & Smooth & Low & Medium \\
\hline THMC 63 & 46 & Vietnam & Spindle & Green & Smooth & Low & Medium \\
\hline THMC 64 & 47 & Vietnam & Spindle & Medium green & Smooth & Medium & Medium \\
\hline THMC 65 & 48 & Vietnam & Spindle & Medium green & Smooth & Low & Medium \\
\hline THMC 345 & 49 & Vietnam & Spindle & Light green & Smooth & Medium & Long \\
\hline THMC 68 & 50 & Bangladesh & Spindle & White & Spiny & Medium & Medium \\
\hline THMC 76 & 51 & Bangladesh & Spindle & Medium green & Spiny & Medium & Medium \\
\hline THMC 77 & 52 & Bangladesh & Spindle & Medium green & Spiny & Low & Medium \\
\hline THMC 81 & 53 & Bangladesh & Spindle & Dark green & Spiny & High & Medium \\
\hline THMC 87 & 54 & Bangladesh & Spindle & Light green & Spiny & Medium & Short \\
\hline THMC 89 & 55 & Bangladesh & Elongated & Light green & Spiny & Medium & Long \\
\hline
\end{tabular}


Table 1. Continued.

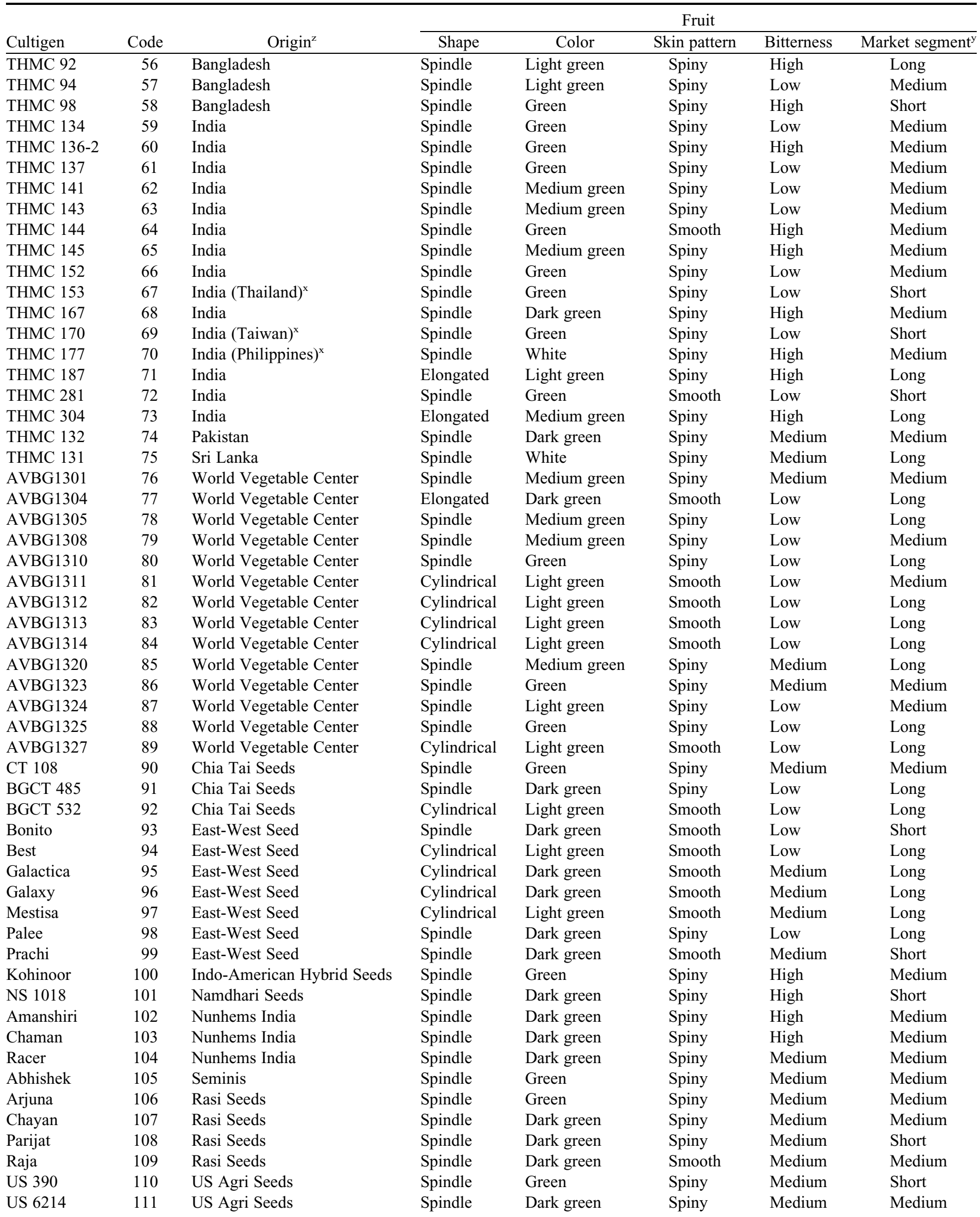


Table 1. Continued.

\begin{tabular}{|c|c|c|c|c|c|c|c|}
\hline \multirow[b]{2}{*}{ Cultigen } & \multirow[b]{2}{*}{ Code } & \multirow[b]{2}{*}{ Origin $^{z}$} & \multicolumn{5}{|c|}{ Fruit } \\
\hline & & & Shape & Color & Skin pattern & Bitterness & Market segment $^{\mathrm{y}}$ \\
\hline VNR 28 & 112 & VNR Seeds & Spindle & Green & Spiny & High & Short \\
\hline VNR 32 & 113 & VNR Seeds & Spindle & Green & Smooth & Medium & Short \\
\hline
\end{tabular}

${ }^{\bar{z}}$ Chia Tai Seeds (Kanchanaburi, Thailand), East-West Seed (Chiang Mai, Thailand), Indo-American Hybrid Seeds (Bangalore, India), Namdhari Seeds (Bangalore, India), Nunhems India (Bangalore, India), Seminis (Bangalore, India), Rasi Seeds (Attur, India), U.S. Agri Seeds (Bangalore, India), VNR Seeds (Raipur, India).

${ }^{\mathrm{y}}$ Market segment is the common terminology used by the bitter gourd breeders globally for classes of bitter gourd based on fruit length.

${ }^{\mathrm{x}}$ Germplasm of these accessions was procured from India, and the country in brackets represents its origin.

electrophoresis, the gels were stained with $5 \mu \mathrm{g} \cdot \mathrm{mL}^{-1}$ ethidium bromide and the bands were visualized under ultraviolet light using the alpha imager system. The details of SSR primer pairs used for the analysis are provided in Table 2. Allele number and frequency were determined in Powermarker V3.0. Diversity analysis based on SSR data was performed in Darwin 6.0.10 (Perrier and Jacquemoud-Collet, 2006) using the Jaccard coefficient $J=a /(n-d)$, where $a$ and $d$ are the number of matches and mismatches, respectively, and $\mathrm{n}$ is the total number of samples, and a phylogenetic tree was constructed by neighborjoining analysis. The genetic distance between groups with common geographic origin, fruit color, shape, and taste was analyzed in Popgene1.32 (Yeh et al., 1999) using Nei's (1978) unbiased genetic identity and genetic distance. The population structure was analyzed based on 50 SSR loci using the software STRUCTURE 2.3.4 (Pritchard et al., 2000). The optimal $k$ value for population structure was determined by the method described by Evanno et al. (2005).

\section{Results}

Fruit trait evaluation. The 114 bitter gourd cultigens were highly diverse for the five fruit traits (Table 1). Three types of fruit shape were identified in the germplasm: cylindrical, spindle, and elongated. The majority of the cultigens produced spindle-shaped fruit $(82.5 \%)$; cylindrical and elongated fruit were produced by $13.2 \%$ and $4.3 \%$ of the cultigens, respectively. Five distinct fruit skin colors were observed in the cultigens: green $(36.9 \%)$, light green $(21.9 \%)$, medium green $(18.4 \%)$, dark green $(17.5 \%)$, and white $(5.3 \%)$. Two fruit skin patterns were found in the cultigens: smooth $(39.5 \%)$ and spiny $(60.5 \%)$. Three classes of bitterness among the cultigens were noted: low (51.8\%), medium (34.2\%), and high (14\%). The cultigens were categorized into three market segments based on the fruit length: long (27.2\%), medium (43.9\%), and short $(29.9 \%)$.

Characterization of SSR loci. The 50 SSR markers detected a total of 202 alleles (with a mean of four alleles per locus) in the 114 cultigens. The major allele frequency ranged from $43.5 \%$ to $97.4 \%$ [mean $75.1 \%$ (Table 2)]. Rare alleles were present exclusively in landraces and in one $F_{1}$ hybrid cultivar (Bonito). All but two of the detected alleles were present in at least one landrace, and 92 of the 202 alleles were exclusively present in the landraces. The allele diversity of the commercial cultivars (60 of the 202 alleles present) was on average, larger than in the landraces (54 of the 202 alleles), as most cultivars were hybrids. The largest number of alleles (and highest degree of heterozygosity) was found in landrace THMC 101. Interestingly, the commercial cultivar Best, an $\mathrm{F}_{1}$ hybrid, was homozygous at all tested alleles. Also, commercial cultivars US 390, NS 1018, Palee, Sagar, US 6214, Chayan, Galactica, Galaxy, and BGCT 532 were comparable to landraces for degree of homozygosity at the tested loci $(<59$ alleles per 50 loci).

We assessed correlations of molecular marker genotypes in terms of genetic distance and the geographical origin among the landraces (Fig. 1A), and the relationship of the molecular diversity with fruit phenotypic characteristics among all entries. It showed that genotypes from India, Bangladesh, and Pakistan were genetically more related to each other than to any other geographical group, with Nei's genetic distance below 0.1 . Similarly, genotypes from Cambodia, Vietnam, Indonesia, and the Philippines clustered together at genetic distances smaller than 0.05 , indicating a common origin and selection history for these landraces. The landrace from Laos was genetically related to the lines from Thailand, but genetically distinct from the rest of the cultigens. The genotypes from Taiwan and Sri Lanka were quite distinct from each other and also from the other countries. Genotypes with spindle or elongated fruit were more related to each other (Nei's genetic distance of 0.2) than to the entries with cylindrical fruit (Fig. 1B), landraces with white fruit color were genetically distinct from the green-colored fruit types (Nei's genetic distance greater than 0.3), and the dark-green genotypes were well separated from the other green genotypes (Fig. 1C). Similarly, low and medium-bitter types were genetically more similar to each other than the bitter genotypes (Fig. 1D).

GENETIC STRUCTURE OF THE BITTER GOURD COLleCtion. Population structure analysis revealed three major subpopulations based on 202 alleles detected by the 50 SSR markers (Fig. 2). All accessions with cylindrical fruit belonged to subpopulation 1, and all accessions of subpopulation 2 had spindleshaped fruit. Spindle fruit form also was found in subpopulations 1 and 3. The elongated fruit form appeared in subpopulations 1 and 3 .

The population structure was reflected by the separation of the entries on a phylogenetic tree (Fig. 3). The three subpopulations (Fig. 2) were represented by three major clusters (Fig. 3). The distribution of cultigens was largely consistent with their geographic origin (Fig. 3). For example, 86\% (24 of 28 ) of the cultigens from India were in subcluster B; $90 \%$ ( 19 of 21) of the cultigens from Philippines were in subcluster $A ; 71 \%$ (10 of 14) of the cultigens of Thai origin were in subcluster C; and $80 \%$ (4 of 5) of the cultigens from Taiwan grouped in subcluster D. All the cultigens from three other south Asian countries (Bangladesh, Pakistan, and Sri Lanka) grouped together along with Indian cultigens in subcluster B. All the cultigens from Indonesia, Vietnam, and Cambodia grouped 
Table 2. Characteristics of the 50 simple sequence repeat (SSR) markers used to characterize genetic diversity in 114 bitter gourd cultigens.

\begin{tabular}{|c|c|c|c|c|c|c|}
\hline SSR name & Forward primer sequence & Reverse primer sequence & SSR motif & $\begin{array}{l}\text { Alleles } \\
\text { (no.) }\end{array}$ & $\begin{array}{c}\text { Major } \\
\text { allele } \\
\text { frequency }(\%)\end{array}$ & $\mathrm{PIC}^{\mathrm{z}}$ \\
\hline$\overline{A V R D C-B G 1}$ & CAAGGAACGCAGAAATCCTA & GAGGTCTGCCTCTTCCAAAA & $(\mathrm{AC}) 12$ & 6 & 43.5 & 0.7426 \\
\hline AVRDC-BG2 & GAGCACACAGAAAATTGGGT & TGATCCACTCCCAATCTTAGC & $(\mathrm{AC}) 8$ & 4 & 70.4 & 0.552 \\
\hline AVRDC-BG3 & GACGGGTCGTTGTAAGGTTT & CCCTGGAAATCAGATGAAGG & $(\mathrm{AG}) 12$ & 3 & 61.7 & 0.4387 \\
\hline AVRDC-BG15 & AGGGCTACCAAAAGCAGAAA & TACGTTGTCATTCCCAAAGC & $(\mathrm{AG}) 7$ & 4 & 93.9 & 0.1674 \\
\hline AVRDC-BG25 & TCGAGATCACGATAGGGACA & CATCACGGCTACTCTTTTCG & $(\mathrm{AG}) 8$ & 6 & 86.1 & 0.3173 \\
\hline AVRDC-BG26 & CAGGGACGACGATTATCTGA & GACCGTCTTTCGATTTCCA & $(\mathrm{AG}) 9$ & 3 & 88.7 & 0.2956 \\
\hline AVRDC-BG27 & GGGGACCAAAGCATTGAA & CAGCTCTGTGAAAGGACCAA & $(\mathrm{AG}) 9$ & 3 & 67.0 & 0.4006 \\
\hline AVRDC-BG29 & GGACATCACACCCAGCAGT & CCAAAAGCAAGAAAGAAGGG & (CA) 8 & 2 & 90.4 & 0.1585 \\
\hline AVRDC-BG30 & CAATTCTACGCGCAACTCAT & GGCTCAGAAAGGAAGCTCAC & (CT) 10 & 4 & 92.2 & 0.217 \\
\hline AVRDC-BG32 & GGAGTTTGTGCGTATGATGG & CCGTCCGATCACCTAAAAAT & (CT)12 & 7 & 60.0 & 0.5819 \\
\hline AVRDC-BG33 & CATTGACTGAAGTTGGCGTT & CATCCACAACTGCTCACACA & (CT) 12 & 5 & 79.1 & 0.3884 \\
\hline AVRDC-BG35 & CACCATGGCCGGTTCTTA & TTCGAAGGCTATTCAGAGGC & $(\mathrm{CT}) 8$ & 3 & 48.7 & 0.5614 \\
\hline AVRDC-BG37 & ATTTCTCCATGTTCTTCCGC & $\begin{array}{l}\text { AAGAGAGAGAGAAAGCGA } \\
\text { GAGC }\end{array}$ & $(\mathrm{CT}) 8$ & 2 & 74.8 & 0.2831 \\
\hline AVRDC-BG41 & TTTACCCTTCCATTACTCGC & CTTGGTGAATCTGGAGAGCA & $(\mathrm{CT}) 9$ & 6 & 80.0 & 0.4232 \\
\hline AVRDC-BG48 & GCAAAAACACTGTCACCCAC & TTCGCTTCTTCCCTCTTCAT & $(\mathrm{GA}) 8$ & 3 & 66.1 & 0.4775 \\
\hline AVRDC-BG49 & CTGAAGGGCAGTGTAACGAA & САСТСССССАТТСТСААСТТ & $(\mathrm{GA}) 8$ & 2 & 62.6 & 0.3705 \\
\hline AVRDC-BG50 & TTAATCCAACCCGTAGGAGC & TGGCCTTTTGCTTCTTAGGT & (GA) 8 & 4 & 85.2 & 0.2943 \\
\hline AVRDC-BG51 & CCCGTTCCCTTGAAACTAAA & TTGGGTGGTGATGAAGTTGT & $(\mathrm{GA}) 9$ & 2 & 67.8 & 0.3604 \\
\hline AVRDC-BG54 & GCAGTTGGTCCACCTTCATA & TTCACTAATCAGTCGCTCGG & (TA) 9 & 2 & 93.0 & 0.1326 \\
\hline AVRDC-BG55 & CCGGGGATCTTCTTCCTTTA & TCGTAGCGAAGATGTGAAGC & (TC) 10 & 4 & 80.0 & 0.3156 \\
\hline AVRDC-BG56 & ATCACCATGGACAAAACCCT & GCACCATCTTGTATCGGTTG & (TC) 10 & 3 & 93.9 & 0.1254 \\
\hline AVRDC-BG57 & GGGACAACACACACCCAAA & CCCATGGAGAAATTTCAGGT & (TC)11 & 2 & 93.9 & 0.1316 \\
\hline AVRDC-BG58 & GGCTCCTTTTCCCAAACTCT & AGATTATGAATTCGCGGTCC & (TC) 12 & 3 & 87.0 & 0.2251 \\
\hline AVRDC-BG59 & GGGGAAAGACAAAGGTAGCA & TCGGACATTTTTGAGCAGAG & (TC) 8 & 3 & 64.3 & 0.4563 \\
\hline AVRDC-BG66 & AGAGGTCTGCCTCTTCCAAA & CAAGGAACGCAGAAATCCTA & $(\mathrm{TG}) 9$ & 5 & 48.7 & 0.7062 \\
\hline AVRDC-BG67 & ACCGTGTGAACCTCTGTCAA & ACCGGTTGTGAAGTGGAAGT & $(\mathrm{AAG}) 8$ & 4 & 91.3 & 0.1794 \\
\hline AVRDC-BG70 & CATAAGGCCTTCCTCTGCTC & CGGGGATTCCACTCTTCTT & $(\mathrm{AGA}) 12$ & 4 & 84.3 & 0.3348 \\
\hline AVRDC-BG71 & TGGACTTGGAAGTGGTGAAA & TCACGACACAATCCACCTTT & $(\mathrm{AGA}) 8$ & 6 & 77.4 & 0.4135 \\
\hline AVRDC-BG73 & GAACGACAAAGGGAAGGAAA & СТTCTTTGCCATCATCCTCA & (AGA) 8 & 4 & 62.6 & 0.4029 \\
\hline AVRDC-BG74 & AACACCTTCTGACTCCACCC & CGTTCAATCCTCTCCTCCTC & $(\mathrm{AGA}) 9$ & 7 & 76.5 & 0.5084 \\
\hline AVRDC-BG75 & AGACTTCCGGTACGAAAACG & TTCTCTCACATGGGAATCCA & (AGA)9 & 5 & 86.1 & 0.2728 \\
\hline AVRDC-BG83 & TATGCAGGGAAGACTGATGG & TTTTGCTGGCTAAGGTGTTG & $(\mathrm{GAA}) 8$ & 6 & 78.3 & 0.4574 \\
\hline AVRDC-BG85 & TGCAACCACTTGGGTTCTAA & CACGCCAGTAGCTTCAACAT & $(\mathrm{GAA}) 8$ & 5 & 55.8 & 0.625 \\
\hline AVRDC-BG86 & AAGGACAGAAGCACAAACCC & TTCCCGAAGCTTCATTCTCT & $(\mathrm{GAA}) 9$ & 3 & 60.9 & 0.4952 \\
\hline AVRDC-BG90 & TGTCTTGGAATTGCTTCTCG & GGAGGAGAAAATGATCGGAA & (TCT) 12 & 6 & 61.7 & 0.5955 \\
\hline AVRDC-BG92 & GGGGAACTATTTGCAATCCA & TGGGGAGTCATAGAACGAGA & $(\mathrm{TCT}) 8$ & 4 & 87.8 & 0.4272 \\
\hline AVRDC-BG93 & CCACTATGACGAATCCGTTG & TTCTTCAAGTCGCTGCTGTT & $(\mathrm{TCT}) 8$ & 3 & 90.4 & 0.1751 \\
\hline AVRDC-BG94 & GGGAGAACACGTTTGGATTT & ATACCCCACACAAAAAGGGA & $(\mathrm{TCT}) 9$ & 6 & 85.2 & 0.292 \\
\hline AVRDC-BG97 & GGTAAAGGAGGCAAGGATGA & GGGGGTTAAGGGATTCATTT & (TTA) 8 & 4 & 85.2 & 0.2717 \\
\hline AVRDC-BG98 & ACTCTTGACCGGCTCGTAGT & CCATGTTTGACGACCTTGAG & (TTC) 8 & 3 & 87.8 & 0.2238 \\
\hline AVRDC-BG99 & TGAAGGCAAATGCTCCTGTA & CCTTCTGGTTGAACAAATGC & (TTC) 9 & 3 & 66.1 & 0.5 \\
\hline AVRDC-BG100 & CGTCTGTTTCTCCATCGAAT & GATCAGAACAAGAAGCGCAG & $(\mathrm{TTC}) 9$ & 4 & 63.5 & 0.5308 \\
\hline AVRDC-BG101 & AACCCCATATTAGACGGTG & CCAGGTTAAGCAATTTCAAG & (GGT)4-(GAA)6 & 2 & 97.4 & 0.1048 \\
\hline AVRDC-BG104 & GTAAACGGCTCTTTAGGGTT & СТСТСТСТGTTCTCTTCСТCTC & $(A G) 9-(A G) 6$ & 10 & 58.3 & 0.6708 \\
\hline AVRDC-BG109 & CCCGTAAGGTTTATTGCAT & ТССТТТССТТСТТСТТСТТС & (AGA)8-(GAA)4 & 4 & 48.7 & 0.4654 \\
\hline AVRDC-BG111 & GAACAAGACTAATCACCCCA & CCAACCACAAGAAGAAGAAG & (CTT)6-(CTT)4 & 2 & 87.0 & 0.2255 \\
\hline AVRDC-BG112 & ACGACGATTATCTGATTGCT & GACCGTCTTTCGATTTCC & (GA)6-(AG)9 & 3 & 88.7 & 0.3053 \\
\hline AVRDC-BG125 & CGGAAGAGGCTTCGAAAT & TTCAGGCTGCTGATTTTCAC & (TC)9 & 4 & 82.6 & 0.3178 \\
\hline AVRDC-BG135 & GCTCCTAACCATCACCCTGT & GGACACAGAATTCCAAAGCC & (TGAG)6 & 4 & 57.4 & 0.4905 \\
\hline AVRDC-BG136 & TCGCAGTCTCATTTCTCAAG & AGTGGCAGAGCGTTTTACCT & (TTC)7 & 5 & 55.7 & 0.6101 \\
\hline AVERAGE & & & & 4 & 75.1 & \\
\hline
\end{tabular}

zPolymorphic information content.

with cultigens from Philippines in subcluster A, and 58\% (7 of 12 ) and $42 \%$ ( 5 of 12 ) of bitter gourd lines released by the World Vegetable Center were scattered in subcluster A and B, respectively. A single cultigen of $M$. balsamina comprised a separate subcluster, E, and was genetically divergent from the genepool of $M$. charantia. 
A)

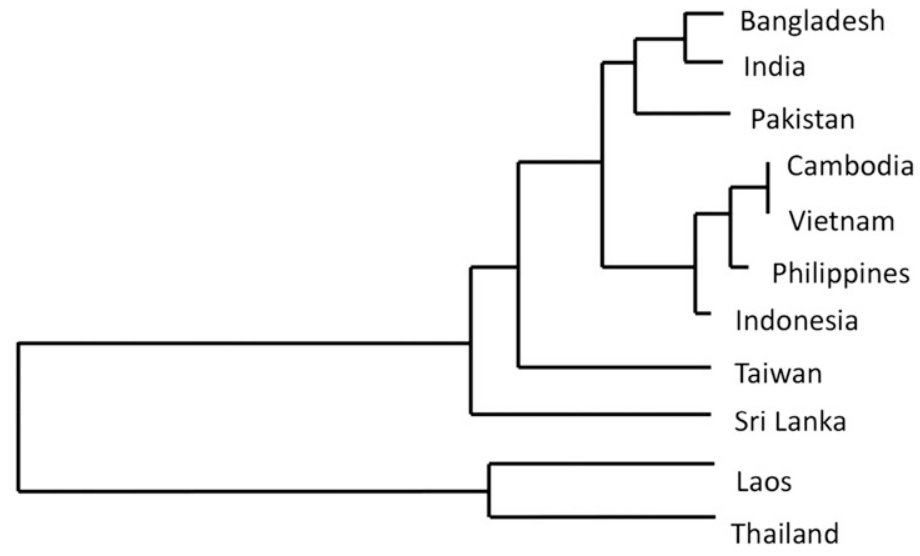

B)

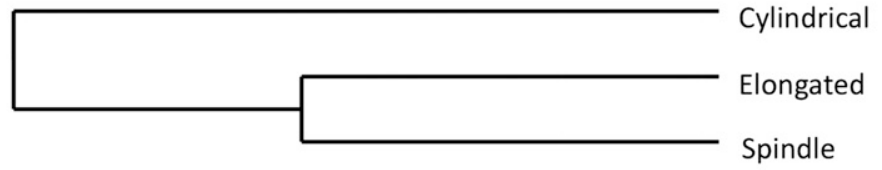

C)

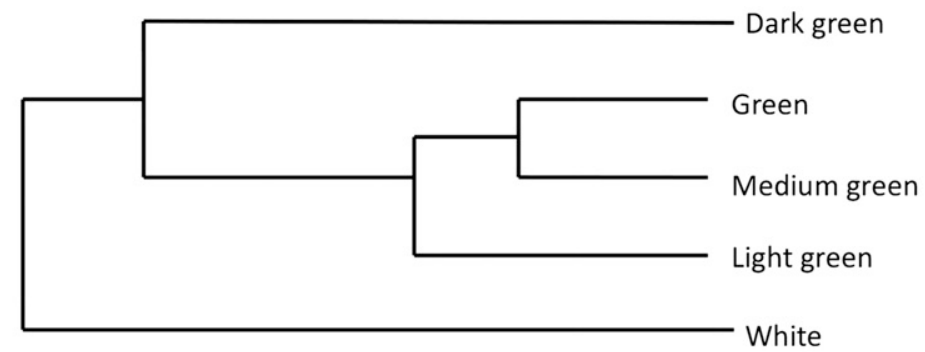

D)
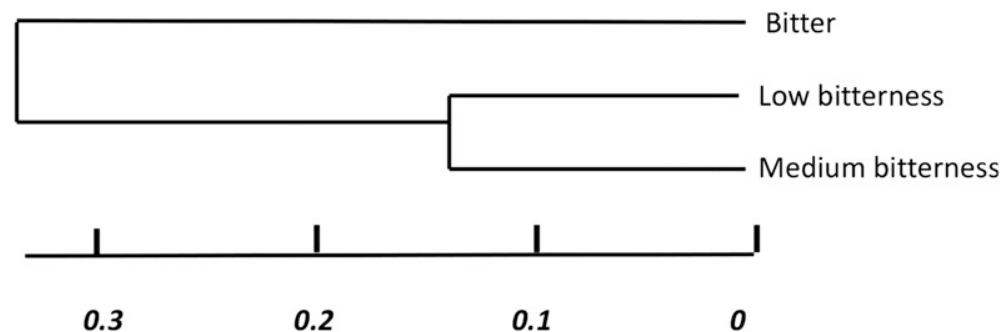

Nei's genetic distance (Nei 1978)

Fig. 1. Genetic diversity of 114 bitter gourd cultigens grouped by (A) country of origin, (B) fruit shape, (C) fruit skin color, and (D) fruit bitterness.

\section{Discussion}

Bitter gourd is an important commercial cucurbitaceous cash crop that is cultivated mainly by smallholder farmers in Asia. The current bitter gourd seed market in Asia is annually worth $\approx 16$ million Euros (N.K. Singh, personal communication). An understanding of the genetic diversity in a given collection of a species is important for curators, geneticists and breeders. We employed SSR analysis to characterize genetic diversity in 114 bitter gourd cultigens that originated from 11 countries that constitute the major bitter gourd growing areas of south and southeast Asia.

The 114 cultigens were divided into three subpopulations based on the SSR analysis (Fig. 2), and were subdivided into five subclusters (Fig. 3). There are clear genetic distinctions between bitter gourd gene pools of southeast Asia (Philippines, Thailand, Vietnam, Cambodia, Indonesia)subclusters $\mathrm{A}$ and $\mathrm{C}$; south Asia (India, Bangladesh, Pakistan, Sri Lanka) - subcluster B; and east Asia (Taiwan) — subcluster D. Shortand medium-fruit segment cultigens were found in the collection that originated from Thailand; short-fruited cultigens were clustered in subcluster $\mathrm{C}$, whereas mediumfruit length cultigens clustered in subcluster A. Cultigen THMC 153 (Code 67), grouped in subcluster $\mathrm{C}$, though collected from India, originated in Thailand (M. Anil, personal communication). Similarly, THMC 114 (Code 10) collected from Laos clustered along with Thai cultigens, and in all probability originated from Thailand because seed of bitter gourd cultivars grown in Laos is imported mostly from Thai seed companies, and human traffic between the two countries is intense and regular. Laos shares $1835 \mathrm{~km}$ of its border with Thailand and does not have a local vegetable seed industry. Thus, it was not unexpected when both THMC 153 and THMC 114 tended to cluster with smallfruited Thai cultigens in cluster $\mathrm{C}$. An active breeding program for small-fruit segment bitter gourd does not exist in Thailand; these cultigens are probably farmer-developed landraces. These small-fruited landraces, locally named as Kee Nuk ("bird droppings") are grown in home gardens in Thailand; farmers selected disease-resistant variants from these populations. Entries originating from eastern Asia (Taiwan) were grouped in subcluster D (Fig. 3). Cultigen THMC 170 (Code 69) was collected from an Indian source but its origin is Taiwan (M. Anil, personal communication). South Asian subcluster B comprises entries from India, Bangladesh, Pakistan, and Sri Lanka (Fig. 3). Within this cluster, landraces originating from eastern India such as THMC 143 (Code 63), THMC 145 (Code 65), THMC 167 (Code 68), THMC 152 (Code 66) were grouped separately and diverged from other cultigens of Indian origin. Cultigens THMC 143 and THMC 167 were resistant to local isolates of cucurbit powdery mildew incited by Podospheara xanthii in trials conducted in 11 locations in Thailand, Vietnam, Taiwan, Philippines, and India (N.P.S. Dhillon, unpublished data).

Bitter gourd landraces that originated from three eastern states of India, Odisha (formerly Orissa), West Bengal, and Jharkhand (formerly part of Bihar state) have been reported to be genetically distinct from bitter gourd collections of other agro-ecological zones of northern and southern parts of India (Gaikwad et al., 2008). Cultigens that originated from Bangladesh were genetically diverse and grouped in three subgroups in subcluster B (Fig. 3). The popular, high-yielding bitter gourd hybrid cultivar Chaman (Nunhems India, Bangalore, India) has 
in its pedigree parents from eastern and southern India ( $R$. Hegde, personal communication). It is a common belief among Asian bitter gourd breeders that crosses between lines derived from bitter gourd gene pools of southern and eastern India, and Bangladesh provide heterosis for early and high yield in many instances (A. Kapur, personal communication).

Short-fruited cultigens were restricted to subclusters B, C, and D, whereas subcluster A contained medium- and longfruited cultigens (Fig. 3). Smooth-skinned cultigens that originated from the Philippines, Thailand, Vietnam, and Cambodia are grouped together in subcluster A (Fig. 3). Cambodia, Vietnam, and Indonesia do not have indigenous bitter gourd breeding programs, and farmers in these countries rely on bitter gourd hybrids introduced by companies such as East-West Seed (EWS), Bulacan, Philippines, and in some instances farmers have developed open-pollinated cultivars from these hybrids through repeated inbreeding and selection. This was observed

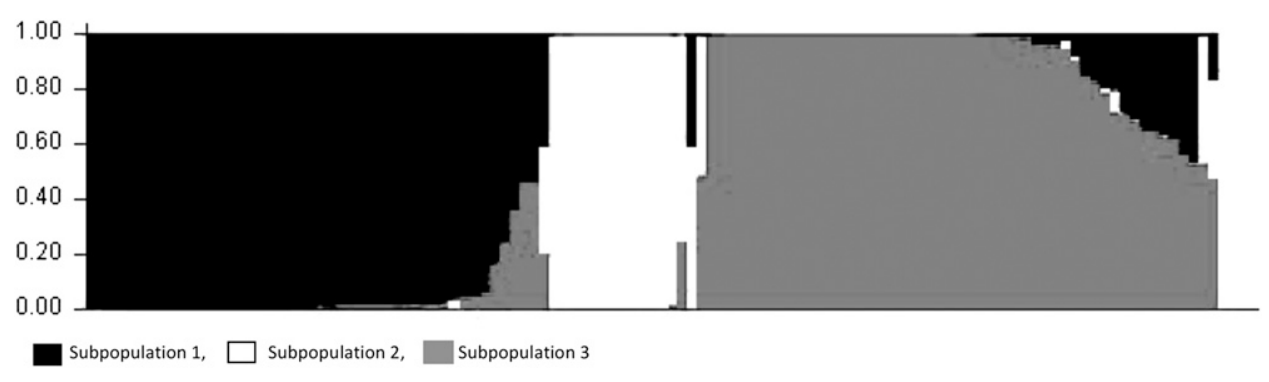

Fig. 2. Population structure analysis of 114 bitter gourd cultigens based on 50 simple sequence repeat markers. by two authors of this paper (N.P.S. Dhillon and S. Sanguansil) during their comprehensive farmers' field visits in southeast Asia and in interactions with growers and seed company breeders. Initially, EWS breeders based their bitter gourd breeding program on a collection of landraces from the Philippines. Thus, in hindsight, it is obvious that cultigens of Philippines origin and hybrid cultivars released by EWS, such as Galactica, Galaxy, Best, Palee, Bonito, Prachi, and Mestisa, and the other cultigens collected from Cambodia, Vietnam, and Indonesia would cluster together in subcluster A (Fig. 3). All the cultigens possessing light-green, smooth, medium-to-long fruit, and low-to-medium bitterness are grouped in subcluster A, whereas green-to-dark green, spiny, medium-to-high bitter and short-fruited cultigens are restricted to south Asian subcluster B (Fig. 3). Wild type bitter gourds are green-to-dark green, spiny, highly bitter and short, and abundantly found in the fields in northeastern India (Gaikwad et al., 2008). Thus, it appears that south Asia is the center of domestication of bitter gourd, and that other types (long, cylindrical, smooth, light green, less bitter) available in southeast Asia are the result of mutations followed by farmer selection according to the needs of the local consumer. Cultigen THMC 281 (Code 72) is genetically distinct from rest of the cultigens used in this study, but it clustered together with accessions of subpopulation 2 (Fig. 3). It is

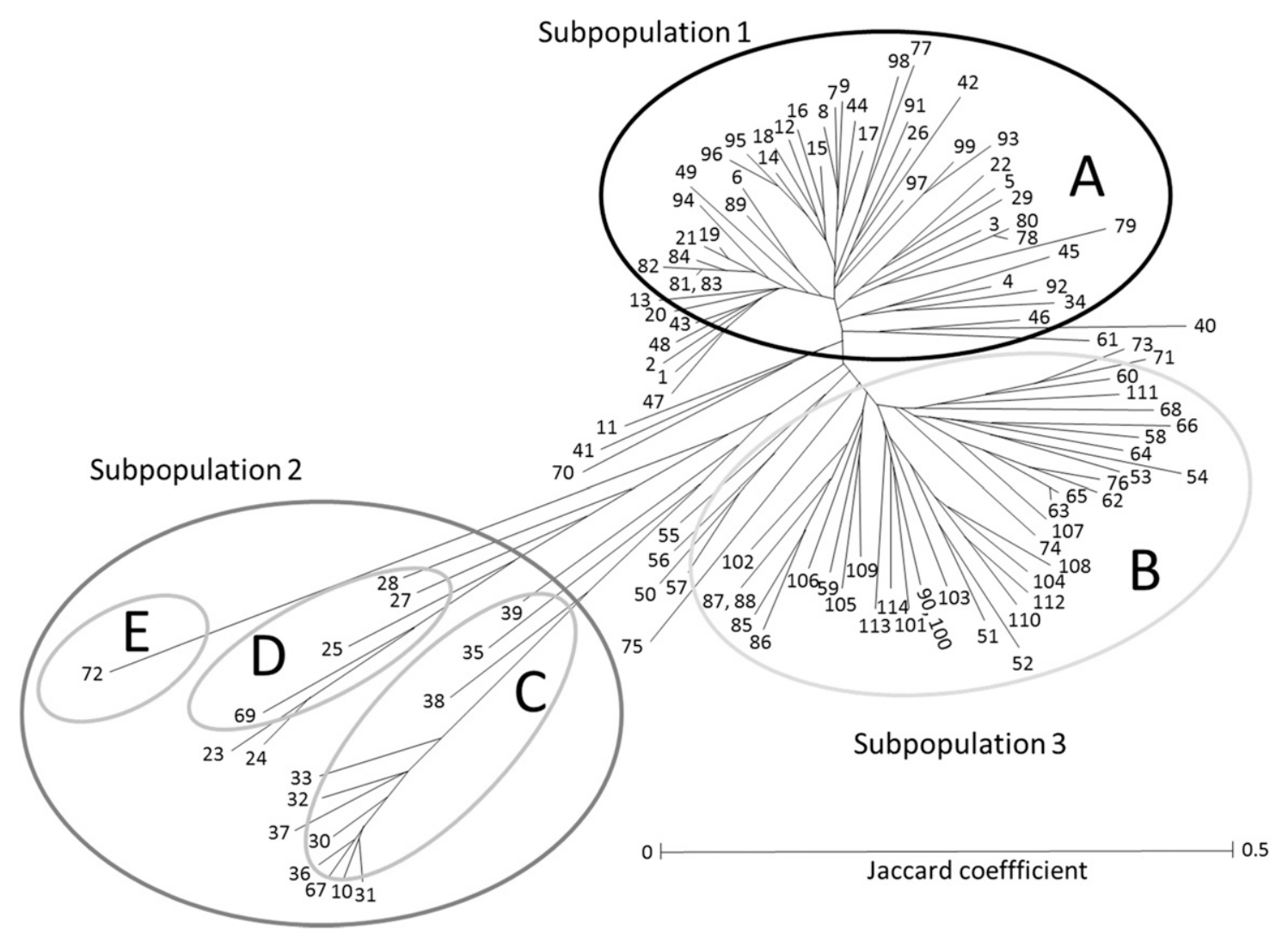

Fig. 3. Phylogenetic tree of 114 bitter gourd cultigens coded in Table 1. 
M. balsamina and it is extremely difficult to obtain hybrids between $M$. charantia $\times M$. balsamina (Bharathi et al., 2012). This cultigen is found growing wild in northern and eastern states of India.

Repeated cycling of a relatively small number of genetically closely related bitter gourd lines in commercial breeding has narrowed the genetic diversity within the commercial bitter gourd crop. For example, VNR 28, a high-yielding bitter gourd cultivar in the short-fruit segment, was released by VNR Seeds (Raipur, India) in 2004. The short fruit segment accounts for $10 \%$ of the Indian bitter gourd seed market, which was estimated at $200 \mathrm{t}$ in 2015 (P. Agarwal, personal communication). Using this germplasm, three other Indian seed companies developed and released three hybrid cultivars in the short fruit segment: Parijat, Racer, and US 390 (Codes 108, 104, and 110, respectively) (M. Anil, personal communication; S. Thippeswamy, personal communication). These three hybrid cultivars are tightly linked together with VNR 28 (Code 112) in subcluster B (Fig. 3), confirming their close genetic relatedness. Similarly, in subcluster A, commercial cultivars Galactica (Code 95) and Galaxy (Code 96) from EWS are grouped together in a single subgroup. Commercial cultivars Prachi, Mestisa, and Bonito (Codes 99, 97, and 93, respectively), released by EWS, are closely related and placed together in subcluster A (Fig. 3). Thus, a narrowing of the bitter gourd genetic base is underway in Asia. Likewise, it has been observed that genetic diversity among commercial cultivars of other cucurbit species such as melon, watermelon and bottle gourd is much less than the overall diversity within these cucurbit crops (Decker-Walters et al., 2001; Levi et al., 2001; Nakata et al., 2005; Sheng et al., 2012; Solmaz et al., 2016). Seed companies are under constant competition and also pressure from the growers to provide new cultivars after a gap of 3 to 4 years. To help ensure their companies will survive in a competitive market, seed company breeders are tempted to use sister lines of a common pedigree to bring new cultivars to market to satisfy demands from growers. Breeders focus mainly on elite $\times$ elite crosses to sustain the breeding progress they have achieved in previous years. This has resulted in genetic uniformity among commercial cultivars of each of the various market segments of bitter gourd, but rendered the bitter gourd crop vulnerable to biotic and abiotic stresses, and limited long-term yield improvement. This trend can be reversed by a conscious effort to introduce additional genetic diversity. Breeders need to evaluate and include wild types, landraces, heirloom cultivars and obsolete cultivars in their hybridization programs. These additional sources of bitter gourd genetic diversity are conserved in situ in various genebanks in Asia. For example, the national genebanks of India store $\approx 1000$ bitter gourd accessions, and the genebanks of the World Vegetable Center and Kasetsart University, Thailand, have 430 and 250 accessions, respectively, available (A. Ebert, personal communication). The Chinese Academy of Agricultural Sciences has 177 bitter gourd accessions stored in several provinces, such as Guangdong, Guangxi and Yunnan (K-L. Hu, personal communication). Additional bitter gourd landraces should be collected for research and breeding. The germplasm from India, China, Bangladesh, and Myanmar, considered important reservoirs of bitter gourd diversity, must be preserved before it is eroded by elite hybrid cultivars. This could be accomplished by an international team of scientists sponsored by one or more international organizations, such as
The Crop Trust, with the approval of germplasm regulators in the source countries. These diverse germplasm resources would then be available for sustainable bitter gourd breeding and production.

In conclusion, our study revealed that the commercial cultivars of bitter gourd for different market segments such as south Asian and southeast Asian types have distinct, narrow genetic bases. Bitter gourd genetic resources originating from south Asia (India, Bangladesh, Sri Lanka), southeast Asia (Philippines, Vietnam, Cambodia, Thailand), and east Asia (Taiwan) are molecularly different from each other. Thus, the bitter gourd germplasm bases of these regions can be broadened by strategic mating among cultigens of different origin.

\section{Literature Cited}

Behera, T.K., S. Behera, L.K. Bharathi, K.J. John, P.W. Simon, and J.E. Staub. 2010. Bitter gourd: Botany, horticulture, breeding. Hort. Rev. 37:101-141.

Bharathi, L.K., A.D. Munshi, T.K. Behera, Vinod, J.K. Joseph, K.V. Bhat, A.B. Das, and A.S. Sidhu. 2012. Production and preliminary characterization of novel inter-specific hybrids derived from Momordica species. Curr. Sci. 103:178-186.

da Maia, L.C., D.A. Palmieri, V.Q. de Souza, M.M. Kopp, F.I.F. de Carvalho, and A.C. de Oliveira. 2008. SSR locator: Tool for simple sequence repeat discovery integrated with primer design and PCR simulation. Intl. J. Plant Genomics 2008:412696.

Dana-Farber Cancer Institute. 2005. The gene indices sequence cleaning and validation script (SeqClean). 14 Sept. 2015. <https:// sourceforge.net/projects/seqclean/files/? source=navbar $>$.

Decker-Walters, D., J. Staub, A. López-Seśe, and E. Nakata. 2001. Diversity in landraces and cultivars of bottle gourd (Lagenaria siceraria; Cucurbitaceae) as assessed by random amplified polymorphic DNA. Genet. Resources Crop Evol. 48:369-380.

Decker-Walters, D.S. 1999. Cucurbits, Sanskrit, and the Indo-Aryans. Econ. Bot. 53:98-112.

Duvick, D.N. 2005. The contribution of breeding to yield advances in maize (Zea mays L.). Adv. Agron. 86:83-145.

Evanno, G., S. Regnaut, and J. Goudet. 2005. Detecting the number of clusters of individuals using the software STRUCTURE: A simulation study. Mol. Ecol. 14:2611-2620.

Fulton, T.M., J. Chunwongse, and S.D. Tanksley. 1995. Microprep protocol for extraction of DNA from tomato and other herbaceous plants. Plant Mol. Biol. Rpt. 13:207-209.

Gaikwad, A.B., T.K. Behera, A.K. Singh, D. Chandel, J.L. Karihaloo, and J.E. Staub. 2008. Amplified fragment length polymorphism analysis provides strategies for improvement of bitter gourd (Momordica charantia L.). HortScience 43:127-133.

Harinantenaina, L., M. Tanaka, S. Takaoka, M. Oda, O. Mogami, M. Uchida, and Y. Asakawa. 2006. Momordica charantia constituents and antidiabetic screening of the isolated major compounds. Chem. Pharmaceutical Bul. 54:1017-1021.

Hu, K.L., Q.M. Fu, G.P. Wang, and Z.H. Hu. 2002. Studies on the genetics of fruit color in bitter gourd (Momordica charantia L.). China Vegetables 6:11-12.

Huang, X. and A. Madan. 1999. CAP3: A DNA sequence assembly program. Genome Res. 9:868-877.

Ji, Y., Y. Luo, B. Hou, W. Wang, J. Zhao, L. Yang, Q. Xue, and X. Ding. 2012. Development of polymorphic microsatellite loci in Momordica charantia (Cucurbitaceae) and their transferability to other cucurbit species. Scientia Hort. 140:115-118.

Keneni, G., E. Bekele, M. Imtiaz, and K. Dagne. 2012. Genetic vulnerability of modern crop cultivars: Causes, mechanism and remedies. Intl. J. Plant Res. 2:69-79.

Khanna, P., S.C. Jain, A. Panagariya, and V.P. Dixit. 1981. Hypoglycemic activity of polypeptide-p from a plant source. J. Nat. Prod. 44:648-655. 
Klomann, S.D., A.S. Mueller, J. Pallauf, and M.B. Krawinkel. 2010. Antidiabetic effects of bitter gourd extracts in insulin resistant $\mathrm{db} / \mathrm{db}$ mice. Brit. J. Nutr. 104:1613-1620.

Krawinkel, M.B. and G.B. Keding. 2006. Bitter gourd (Momordica charantia): A dietary approach to hyperglycemia. Nutr. Rev. 64:331-337.

Levi, A., C.E. Thomas, T.C. Wehner, and X. Zhang. 2001. Low genetic diversity indicates the need to broaden the genetic base of cultivated watermelon. HortScience 36:1096-1101.

Liu, K. and S.V. Muse. 2005. PowerMarker: An integrated analysis environment for genetic marker analysis. Bioinformatics 21:21282129.

Liu, Z.G., M.H. Long, R.Y. Qin, and X.Y. Wang. 2005. Studies on genetic variation, correlation and path analysis in bitter gourd (Momordica charantia L.). Guangxi Bot. 25:426-430.

McCreight, J.D., J.E. Staub, T.C. Wehner, and N.P.S. Dhillon. 2013. Gone global: Familiar and exotic cucurbits have Asian origins. HortScience 48:1078-1089.

Morgan, W. and D. Midmore. 2002. Bitter melon in Australia. Rural Ind. Res. Dev. Corp. Publ. No. 02/134.

Nagy, S., P. Poczai, I. Cernák, A.M. Gorji, G. Hegedűs, and J. Taller. 2012. PICcalc: An online program to calculate polymorphic information content for molecular genetic studies. Biochem. Genet. 50:670-672.

Nakata, E., J.E. Staub, A.I. López-Seśe, and N. Katzir. 2005. Genetic diversity of Japanese melon cultivars (Cucumis melo L.) as accessed by random amplified polymorphic DNA and simple sequence repeat markers. Genet. Resources Crop Evol. 52:405-419.

Nei, M. 1978. Estimation of average heterozygosity and genetic distance from a small number of individuals. Genetics 89:583-590.

Oishi, Y., T. Sakamoto, H. Udagawa, H. Taniguchi, K. KobayashiHattori, Y. Ozawa, and T. Takita. 2007. Inhibition of increases in blood glucose and serum neutral fat by Momordica charantia saponin fraction. Biotechnol. Appl. Biochem. 71:735-740.

Perrier, X. and J.P. Jacquemoud-Collet. 2006. DARwin software. 10 Mar. 2016. <http://darwin.cirad.fr/>.

Pritchard, J.K., M. Stephens, and P. Donnelly. 2000. Inference of population structure using multilocus genotype data. Genetics 155:945-959.

Saxena, S., A. Singh, S. Archak, T.K. Behera, J.K. John, S.U. Meshram, and A.B. Gaikwad. 2015. Development of novel simple sequence repeat markers in bitter gourd (Momordica charantia L.) through enriched genomic libraries and their utilization in analysis of genetic diversity and cross-species transferability. Appl. Biochem. Biotechnol. 175:93-118.

Schaefer, H. and S.S. Renner. 2010. A three-genome phylogeny of Momordica (Cucurbitaceae) suggests seven returns from dioecy to monoecy and recent long-distance dispersal to Asia. Mol. Phylogenet. Evol. 54:553-560.

Sheng, Y., F. Luan, F. Zhang, and A.R. Davis. 2012. Genetic diversity within Chinese watermelon ecotypes compared with germplasm from other countries. J. Amer. Soc. Hort. Sci. 137:144-151.

Smit, A.F.A., R. Hubley, and P. Green. 1997. RepeatMasker. 14 Sept. 2015. <http://repeatmasker.org $>$.

Solmaz, I., Y.A. Kacar, N. Sari, and O. Simsek. 2016. Genetic diversity within Turkish watermelon [Citrullus lanatus (Thunb.) Matsumura \& Nakai] accessions revealed by SSR and SRAP markers. Turk. J. Agr. For. 40:1511-1526.

Suribabu, B., N.E. Reddy, and M. Ramarao. 1986. Inheritance of certain quantitative and qualitative characters in bitter gourd (Momordica charantia L.). South Indian Hort. 34:380-382.

Tan, M.J., J.M. Ye, N. Turne, C. Hohnen-Behrens, C.Q. Ke, C.P. Tang, T. Chen, H.C. Weiss, E.R. Gesing, A. Rowland, D.E. James, and Y. Ye. 2008. Antidiabetic activities of triterpenoids isolated from bitter melon associated with activation of the AMPK pathway. Chem. Biol. 15:263-273

Tan, S.P., C.T.C. Kha, S.E. Parks, and P.D. Roach. 2016. Bitter melon (Momordica charantia L.) bioactive composition and health benefits: A review. Food Rev. Intl. 32:181-202.

Uebanso, T., H. Arai, Y. Taketani, M. Fukaya, H. Yamamoto, A. Mizuno, K. Uryu, T. Hada, and E. Takeda. 2007. Extracts of Momordica charantia suppress postprandial hyperglycemia in rats. J. Nutr. Sci. Vitaminol. (Tokyo) 53:482-488.

Vahab, M.A. 1989. Homeostatic analysis of components of genetic variance and inheritance of fruit colour, fruit shape, and bitterness in bitter gourd (Momordica charantia L.). Kerala Agr. Univ., Thrissur, India, PhD Diss.

Walters, T.W. and D. Decker-Walters. 1988. Balsampear (Momordica charantia, Cucurbitaceae). Econ. Bot. 42:286-288.

World Health Organization. 2016. Global report on diabetes. 1 Mar. 2016. <http://www.who.int/diabetes/global-report/en/>.

Yang, P., X. Li, M.J. Shipp, J.M. Shockey, and E.B. Cahoon. 2010. Mining the bitter melon (Momordica charantia L.) seed transcriptome by 454 analysis of non-normalized and normalized cDNA populations for conjugated fatty acid metabolism-related genes. BMC Plant Biol. 10:250.

Yang, S.L. and T.W. Walters. 1992. Ethnobotany and the economic role of the Cucurbitaceae in China. Econ. Bot. 46:349-367.

Yeh, F.C., R.-C. Yang, and T. Boyle. 1999. PopGene version 1.31. Microsoft Window-based free ware for population genetic analysis. 14 Sept. 2015. $<$ https://www.ualberta.ca/ fyeh/popgene_download.html $>$. Yuwai, K.E., K.S. Rao, C. Kaluwin, P.G. Jones, and D.E. Rivett. 1991. Chemical composition of Momordica charantia L. fruits. J. Agr. Food Chem. 39:1762-1763. 